\title{
Correlation between BNT162b2 mRNA Covid-19 vaccine-associated hypermetabolic lymphadenopathy and humoral immunity in patients with hematologic malignancy
}

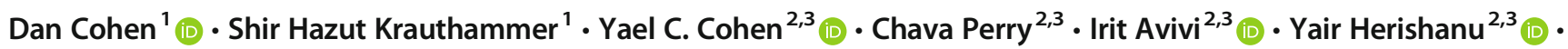 \\ Einat Even-Sapir ${ }^{1,3}$ (D)
}

Received: 5 April 2021 / Accepted: 25 April 2021 / Published online: 8 May 2021

(C) The Author(s), under exclusive licence to Springer-Verlag GmbH Germany, part of Springer Nature 2021

\begin{abstract}
Purpose Vaccine-associated hypermetabolic lymphadenopathy (VAHL) is frequently observed on $\left[{ }^{18}\right.$ F $]$ FDG PET-CT following BNT162b2 administration. Recent data suggest a prominent B cell germinal-center (GC) response elicited by mRNA vaccines in draining lymph nodes. Thus, in this study we aimed to explore the correlation between VAHL and humoral immunity as reflected by post-vaccination serologic testing and by comparing the incidence of VAHL between lymphoma patients treated recently with $\mathrm{B}$ cell depleting therapy and those that were not.

Methods A total of 137 patients with hematologic malignancy that had post-vaccination $\left[{ }^{18} \mathrm{~F}\right]$ FDG PET-CT were included (AllPET group), 86 received both vaccine doses before imaging (PET-2 group). Their VAHL status and grade on imaging were recorded. Among 102 lymphoma patients, 34 (33.3\%) were treated during the year prior vaccination with anti-CD20 antibody containing therapy. A subgroup of 54 patients also underwent serologic testing $2-3$ weeks after the booster dose, and their antispike titers were recorded and graded as well.

Results The overall incidence of VAHL in patients with hematologic malignancy was $31.4 \%$. The 34 lymphoma patients treated during the year prior vaccination with anti-CD20 antibody containing therapy had significantly lower rates of VAHL comparted with all other lymphoma patients ( 8.8 versus $41.2 \%$ in all-PET patients, $\mathrm{Pv}<0.01$ ). VAHL rates were $10 \%$ in patients with negative serology, $31.3 \%$ in patients with low anti-spike titers, and $72.2 \%$ in patients with high anti-spike titers. The positive predictive values of VAHL were 90 and $93.3 \%$ in all-PET and PET-2 patients, respectively. A positive statistically significant correlation was found between VAHL and serology ranks in All-PET patients $\left(\mathrm{r}_{\mathrm{s}}=0.530, \mathrm{Pv}<0.001\right)$, and stronger correlation was found in PET-2 patients $\left(\mathrm{r}_{\mathrm{s}}=0.642, \mathrm{Pv}<0.001\right)$.

Conclusion VAHL on $\left[{ }^{18} \mathrm{~F}\right] \mathrm{FDG}$ PET-CT of patients with hematologic malignancy may reflect GC B cell proliferation and an effective humoral response elicited by BNT162b2 vaccine.
\end{abstract}

Keywords Humoral immunity $\cdot$ Vaccination $\cdot$ Anti-CD20 $\cdot$ Hematology $\cdot$ Functional imaging

This article is part of the Topical Collection on Hematology.

Einat Even-Sapir

evensap@tlvmc.gov.il

1 Department of Nuclear Medicine, Tel-Aviv Sourasky Medical Center, 6 Weizmann St, 6423906 Tel Aviv, Israel

2 Institute of Hematology, Tel-Aviv Sourasky Medical Center, 6 Weizmann St, 6423906 Tel Aviv, Israel

3 Sackler Faculty of Medicine, Tel Aviv University, Tel Aviv, Israel

\section{Introduction}

Data on the immune response elicited by anti-SARS-CoV-2 vaccines is being accumulated in various patient cohorts [1-4]. Polack et al. investigated the safety and efficacy of the BNT162b2 mRNA Covid-19 vaccine in healthy adults or those with chronic stable medical conditions, excluding patients treated with immunosuppressive therapies or diagnosed with immunocompromising conditions [1]. It was later observed that in immunocompromised patients, the elicited immune response to mRNA Covid-19 vaccine is reduced [2, 3]. Boyarsky et al. showed the poor humoral response elicited 
in a study of 346 solid organ transplant recipients [2]. MoninAldama et al. showed that the post-BNT162b2 immune efficacy was strikingly low in solid cancer patients and even lower in patients with hematologic malignancy [3].

In a study of 261 patients with cancer, Thakkar et al. showed the significantly lower seroconversion observed in patients with hematological malignancy after Covid-19 infection, particularly in patients exposed to anti-CD20 antibody containing therapy [5]. B cell depletion by treatment with rituximab or obinutuzumab can also cause suppression of the immune response to vaccines [6-11]. These monoclonal antibodies act against the surface antigen protein CD20 expressed on B lymphocyte during most of its developmental stages [12]. A study on rheumatic patients found that rituximab-treated patients had decreased responses to pneumococcal polysaccharide vaccine [7]. Another study found that Influenza vaccine responsiveness was poor in patients on rituximab [8]. In light of such results, several groups advise patients to consider the timing of Covid-19 vaccination relative to their anti-CD20 antibody therapy schedule [9-11].

Detection of regional lymphadenopathy after Covid-19 vaccines on various imaging modalities has been reported in case reports and small cohorts [13-25]. Recently, our group reported the incidence and time of appearance of BNT162b2 vaccine-associated hypermetabolic lymphadenopathy (VAHL) on $\left[{ }^{18}\right.$ F]FDG PET-CT [26].

While VAHL was reported after other vaccines in the past [27-29], no data exist on the correlation between VAHL and immunogenicity. In this study on patients with hematologic malignancy, we aimed to explore the potential correlation between the phenomenon of reactive lymph nodes identified as hypermetabolic nodes on post-vaccination $\left[{ }^{18} \mathrm{~F}\right]$ FDG PET-CT and the humoral immunity of the patient reflected by postvaccination serologic testing and by comparing between patients treated recently with anti-CD20 antibody containing therapy and patients with similar disease not treated recently with B cell depleting treatment.

\section{Methods}

\section{Patient population}

Since the introduction of the mass vaccination campaign against Covid-19 in late 2020 [30] and after receiving the consent of the institutional ethical committee, all patients over 16 years of age referred for whole-body $\left[{ }^{18} \mathrm{~F}\right] \mathrm{FDG}$ PET-CT in our department were interviewed regarding the dates of the vaccine doses they had and the site of injections [26]. Between December 27, 2020 and March 8, 2021, 150 vaccinated patients with hematologic malignancy that were clinically evaluated and treated at the hematology institute at Tel-Aviv Soursaky Medical Center were referred for $\left[{ }^{18} \mathrm{~F}\right] \mathrm{FDG}$ PET-CT in our department. Thirteen patients with malignant axillary and supraclavicular hypermetabolic lymphadenopathy (MHL) [26] were excluded. All other 137 vaccinated patients consist the study cohort (All-PET group) and include 102 lymphoma patients (86 Non-Hodgkin lymphoma; 16 Hodgkin lymphoma), 34 multiple myeloma patients, and one patient with chronic lymphocytic leukemia (CLL). Fifty-one of the patients received the first vaccine dose only (PET-1 group) and 86 received both the first and booster vaccine doses (PET-2 group) before imaging.

Among the 102 lymphoma patients, 34 (33.3\%) were treated with anti-CD20 antibody containing regimen (30 with rituximab, 4 with obinutuzumab) during the 12 months prior to vaccination, median interval between last therapy and vaccination was 2.63 (IQR 0.70-5.98) months. The other 68 lymphoma patients included: 22 treatment-naïve patients, 22 who were treated with anti-CD20 antibody containing regimen > 12 month before vaccination (median interval 41.73, IQR 26.53-83.50 months), 19 received other systemic therapy (15 for Hodgkin lymphoma, 4 for $\mathrm{T}$ cell lymphoma), and 5 received other therapies in the past.

A total of 54 patients (16 PET-1 patients and 38 PET-2 patients) underwent serologic testing following the booster vaccine dose and were included in a subgroup analysis. Median time interval between the booster vaccine dose and serology testing was 17 (IQR 14.75-21) days. Table 1 and Table 2 summarize the characteristics of the total study cohort and the subgroup cohort, respectively.

\section{Imaging}

$\left[{ }^{18} \mathrm{~F}\right]$ FDG PET-CT studies were performed on PET-CT scanners (GE Healthcare; DISCOVERY 690 and DISCOVERY MI; 7 to 8 frames; frame time $1.5-3 \mathrm{~min}$ ) according to our standard protocol [26]. Imaging data was reviewed, and the presence or absence of "hot" axillary or supraclavicular lymph nodes (ASLN) ipsilateral to the vaccine injection site was recorded. Thus, scans were categorized as showing vaccineassociated hypermetabolic lymphadenopathy (VAHL) or no VAHL if no "hot" nodes were detected. All VAHL were graded on the 4 grade scale described in our recent paper [26]: Grade 1, mild $\left[{ }^{18} \mathrm{~F}\right] \mathrm{FDG}$-uptake intensity (SUVmax < 2.2); Grade 2, moderate $\left[{ }^{18} \mathrm{~F}\right]$ FDG-uptake intensity $(2.2 \leq$ SUVmax $<4$ ); Grade 3 , high $\left[{ }^{18} \mathrm{~F}\right] \mathrm{FDG}$-uptake intensity (SUVmax $\geq 4$ ) in normal-size nodes; and Grade 4, high $\left[{ }^{18}\right.$ F]FDG-uptake intensity (SUVmax $\geq 4$ ) in enlarged nodes.

\section{Serology testing}

Blood serum was collected 2-3 weeks after administration of the second BNT162b2 vaccine dose. Serum samples were analyzed by using Elecsys ${ }^{\circledR}$ Anti-SARS-CoV-2S 
Table 1 Study population characteristics

\begin{tabular}{llll}
\hline & $\begin{array}{l}\text { All patients with } \\
\text { hematologic } \\
\text { malignancy } \\
(n=137)\end{array}$ & Lymphoma patients & Myeloma patients \\
& $68.5(58.4-76.1)$ & $68.4(58.4-76.8)$ & $68.3(56.1-74.9)$ \\
Age (years) & $75(54.7 \%)$ & $52(51.0 \%)$ & $22(64.7 \%)$ \\
Male & $51(37.2 \%)$ & $39(38.2 \%)$ & $11(32.4 \%)$ \\
PET-1 patients & $10(6-15)$ & $10(5-15)$ & $12(8-16)$ \\
$\quad$ Days from Vac-1 to PET-CT & $86(62.8 \%)$ & $63(61.8 \%)$ & $23(67.6 \%)$ \\
PET-2 patients & $19(10-27)$ & $17(10-27)$ & $22(11-30)$ \\
$\quad$ Days from Vac-2 to PET-CT & $26(19.0 \%)$ & $20(19.6 \%)$ & $6(17.6 \%)$ \\
Staging & $59(43.1 \%)$ & $38(37.3 \%)$ & $20(58.8 \%)$ \\
Monitor response to therapy & $22(16.1 \%)$ & $18(17.6 \%)$ & $4(11.8 \%)$ \\
Recurrence & $30(21.9 \%)$ & $26(25.5 \%)$ & $4(11.8 \%)$ \\
Follow-up with NED & & &
\end{tabular}

Categorical variables are reported as frequency and percentage; Continuous variables are reported as median and IQR. Vac-1, first vaccine dose; Vac-2, booster vaccine dose; NED, no evidence of disease assay on the cobas e 601 (Roche Diagnostics) for the quantitative detection of antibodies, predominantly $\operatorname{IgG}$, aimed at the SARS-CoV-2 spike protein receptor binding domain. This assay has a measurement range of 0.40 $250 \mathrm{U} / \mathrm{mL}$, with measured antibody concentration of $<$ $0.80 \mathrm{U} / \mathrm{mL}$ considered as negative and $\geq 0.80 \mathrm{U} / \mathrm{mL}$ as positive. When sample results exceeded the upper limit of the measuring range, antibody concentration was quantitated by on-board dilution. For the purpose of the current study, antibody concentration $\geq 0.80 \mathrm{U} / \mathrm{mL}$ but $<250 \mathrm{U} /$ $\mathrm{mL}$ was graded as low titer and antibody concentration $\geq$ $250 \mathrm{U} / \mathrm{mL}$ was graded as high titer. To ensure that none of the patients had been recently exposed to SARS-CoV2 , an added test was run for the presence of antibodies to SARS-CoV-2 nucleocapsid by the Elecsys ${ }^{\circledR}$ Anti-SARSCoV-2 assay using the cobas e 601 (Roche Diagnostics).

\section{Statistical analysis}

Categorical variables were reported as frequency and percentage. Continuous variables were evaluated for normal distribution and reported as median and interquartile range (IQR). Chi-square test and Fisher's exact test were applied to compare proportions between groups. Independent samples
Table 2 Characteristics of the subgroup of patients with postvaccination serology testing

\begin{tabular}{llll}
\hline & $\begin{array}{l}\text { All patients with } \\
\text { hematologic malignancy } \\
(n=54)\end{array}$ & $\begin{array}{l}\text { Lymphoma patients } \\
(n=33)\end{array}$ & $\begin{array}{l}\text { Myeloma patients } \\
(n=20)\end{array}$ \\
\hline Age (years) & $\begin{array}{l}68.8 \\
(61.2-76.8)\end{array}$ & $\begin{array}{c}(56.6 \\
(52.3-76.4)\end{array}$ & $70.7(63.5-77.0)$ \\
Male & $32(59.3 \%)$ & $19(57.6 \%)$ & $12(60.0 \%)$ \\
PET-1 patients & $16(29.6 \%)$ & $8(24.2 \%)$ & $7(35.0 \%)$ \\
Days from Vac-1 to PET-CT & $11(7-15.75)$ & $10(4-14.75)$ & $14(10-17)$ \\
Days from PET-CT to Serology & $29.5(21-34.5)$ & $32(21-37.25)$ & $26(21-31)$ \\
PET-2 patients & $38(70.4 \%)$ & $25(75.8 \%)$ & $13(65.0 \%)$ \\
Days from Vac-2 to PET-CT & $17(10-31)$ & $14(9-28)$ & $25(11.5-32.5)$ \\
Days from PET-CT to Serology & $0.5(-12-8)$ & $1(-9.5-9.5)$ & $-4(-13.5-5)$ \\
Days from Vac-2 to serology & $17(14.75-21)$ & $17(15-21.5)$ & $16.5(14.25-21)$ \\
Staging & $7(13.0 \%)$ & $3(9.1 \%)$ & $4(20.0 \%)$ \\
Monitor response to therapy & $35(64.8 \%)$ & $21(63.6 \%)$ & $13(65.0 \%)$ \\
Recurrence & $3(5.6 \%)$ & $2(6.1 \%)$ & $1(5.0 \%)$ \\
Follow-up with NED & $9(16.7 \%)$ & $7(21.2 \%)$ & $2(10.0 \%)$ \\
\hline
\end{tabular}

Categorical variables are reported as frequency and percentage; Continuous variables are reported as median and IQR. Vac-1, first vaccine dose; Vac-2, booster vaccine dose; NED, no evidence of disease 
Kruskal-Wallis test and Mann-Whitney test were used to compare continuous variables. Spearman's rank-order correlation was run to determine the relationship between ordinal variables. All statistical tests were performed using SPSS Statistics Version 27 (IBM, Armonk, NY, USA) and were two-sided and $\mathrm{Pv}<0.05$ was considered statistically significant.

\section{Results}

\section{Vaccine-associated hypermetabolic lymphadenopathy in patients with hematologic malignancy}

The incidences of VAHL among vaccinated patients with hematologic malignancy were $31.4,25.5$, and $34.9 \%$ in AllPET, PET-1, and PET-2 groups, respectively. Table 3 details the incidences of VAHL also for lymphoma and myeloma patients separately.

Comparing lymphoma and myeloma patients, myeloma patients had non-significant higher rates of VAHL: 35.3 versus $30.4 \%$ in All-PET group, 27.3 versus $25.6 \%$ in PET-1 group, and 39.1 versus $33.3 \%$ in PET-2 group (Fig. 1, upper row).
Among the 102 vaccinated lymphoma patients, 34 $(33.3 \%)$ were treated with anti-CD20 antibodies during the year before vaccination (median time since last therapy was 2.63 months). The incidence of VAHL in patients recently treated with anti-CD20 antibody containing regimen was significantly lower compared with other lymphoma patients in All-PET, PET-1, and PET-2 patients (Fig. 1, lower row). Only 3 of 34 (8.8\%) lymphoma patients recently treated with anti-CD20 antibody containing therapy showed VAHL on their $\left[{ }^{18} \mathrm{~F}\right] \mathrm{FDG}$ PET-CT study, compared with $41.2 \%$ lymphoma patients not treated recently with anti-CD20 antibodies. Of note, 2 of the 3 VAHL-positive patients treated with antiCD20 antibody containing regimen during the last year received the last treatment 9.8 and 11.8 months before vaccination.

\section{The relationship between vaccine-associated hyper- metabolic lymphadenopathy and post-vaccination antibody secretion}

In 54 patients, post-vaccination $\left[{ }^{18} \mathrm{~F}\right] \mathrm{FDG}$ PET-CT studies and serologic analysis were performed. Sixteen of them had their imaging study after the first vaccine dose, and the median interval between imaging and serology analysis was 29.5 (IQR
Table 3 VAHL incidences in the study groups

\begin{tabular}{|c|c|c|c|c|}
\hline \multirow[t]{6}{*}{$\begin{array}{l}\text { All-PET group } \\
(n=137)\end{array}$} & & $\begin{array}{l}\text { All patients with hematologic } \\
\text { malignancy }\end{array}$ & $\begin{array}{l}\text { Lymphoma } \\
\text { patients }\end{array}$ & $\begin{array}{l}\text { Myeloma } \\
\text { patients }\end{array}$ \\
\hline & & $(n=137)$ & $(n=102)$ & $(n=34)$ \\
\hline & no VAHL & $94(68.6 \%)$ & $71(69.6 \%)$ & $22(64.7 \%)$ \\
\hline & VAHL & $43(31.4 \%)$ & $31(30.4 \%)$ & $12(35.3 \%)$ \\
\hline & grade $1-2 \mathrm{VAHL}$ & $31(22.6 \%)$ & $21(20.6 \%)$ & $10(29.4 \%)$ \\
\hline & grade $3-4$ VAHL & $12(8.8 \%)$ & $10(9.8 \%)$ & $2(5.9 \%)$ \\
\hline \multirow[t]{6}{*}{$\begin{array}{l}\text { PET-1 group } \\
(n=51)\end{array}$} & & $\begin{array}{l}\text { All patients with hematologic } \\
\text { malignancy }\end{array}$ & $\begin{array}{l}\text { Lymphoma } \\
\text { patients }\end{array}$ & $\begin{array}{l}\text { Myeloma } \\
\text { patients }\end{array}$ \\
\hline & & $(n=51)$ & $(n=39)$ & $(n=11)$ \\
\hline & no VAHL & $38(74.5 \%)$ & $29(74.4 \%)$ & $8(72.7 \%)$ \\
\hline & VAHL & $13(25.5 \%)$ & $10(25.6 \%)$ & $3(27.3 \%)$ \\
\hline & grade1-2 VAHL & $11(21.6 \%)$ & $9(23.1 \%)$ & $2(18.2 \%)$ \\
\hline & grade $3-4$ VAHL & $2(3.9 \%)$ & $1(2.6 \%)$ & $1(9.1 \%)$ \\
\hline \multirow[t]{6}{*}{$\begin{array}{l}\text { PET-2 group } \\
(n=86)\end{array}$} & & $\begin{array}{l}\text { All patients with hematologic } \\
\text { malignancy }\end{array}$ & $\begin{array}{l}\text { Lymphoma } \\
\text { patients }\end{array}$ & $\begin{array}{l}\text { Myeloma } \\
\text { patients }\end{array}$ \\
\hline & & $(n=86)$ & $(n=63)$ & $(n=23)$ \\
\hline & no VAHL & $56(65.1 \%)$ & $42(66.7 \%)$ & $14(60.9 \%)$ \\
\hline & VAHL & $30(34.9 \%)$ & $21(33.3 \%)$ & $9(39.1 \%)$ \\
\hline & grade $1-2$ VAHL & $20(23.3 \%)$ & $12(19.0 \%)$ & $8(34.8 \%)$ \\
\hline & grade $3-4 \mathrm{VAHL}$ & $10(11.6 \%)$ & $9(14.3 \%)$ & $1(4.3 \%)$ \\
\hline
\end{tabular}

Categorical variables are reported as frequency and percentage. All-PET group refers to all patients with hematologic malignancy that underwent $\left[{ }^{18}\right.$ F]FDG PET-CT after BNT162b2 administration. PET-1 group includes those received the first vaccine dose only before imaging, and PET-2 group includes those received the booster dose as well 
All-PET group

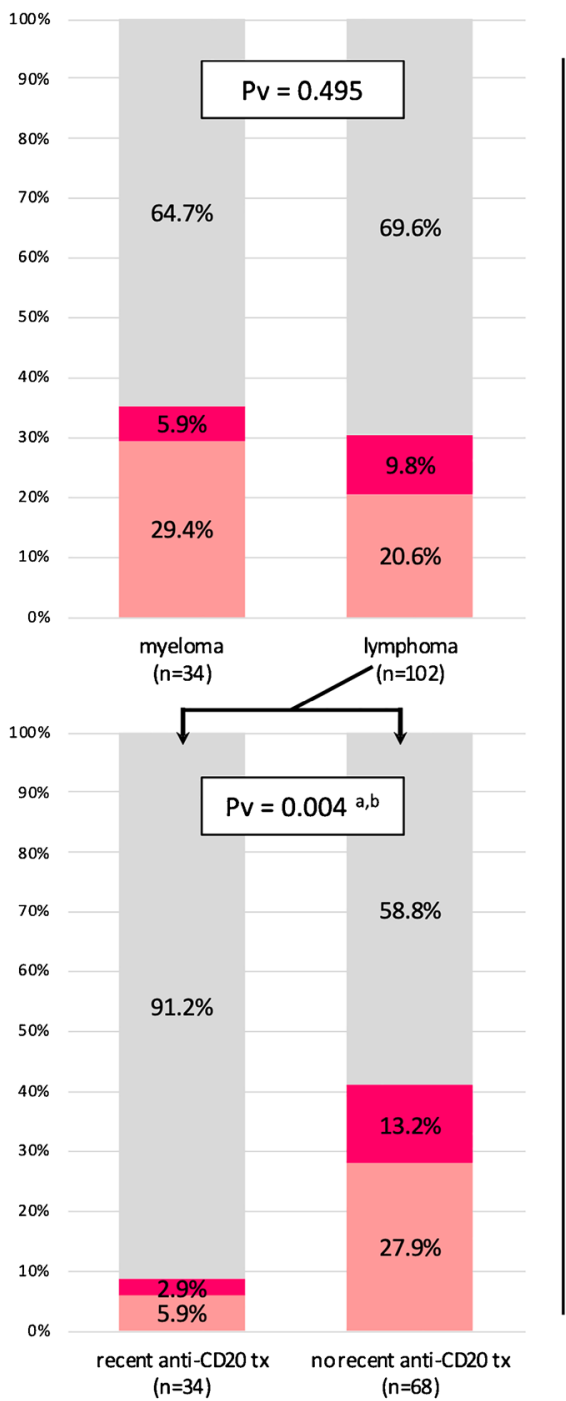

PET-1 group

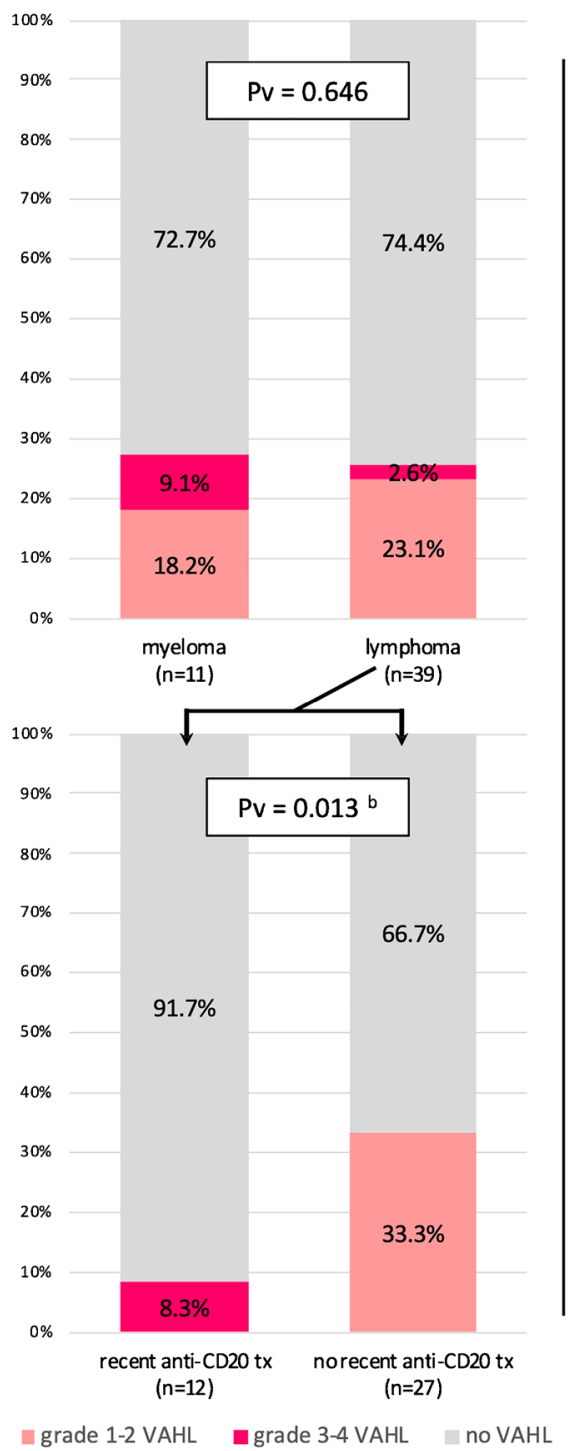

PET-2 group

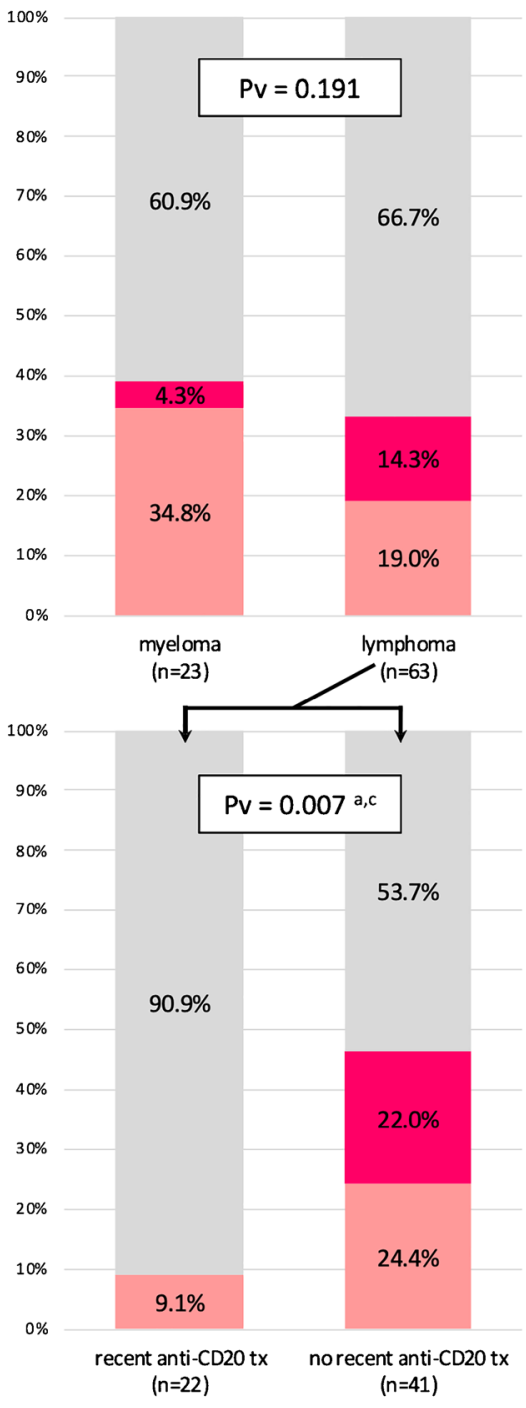

Fig. 1 Vaccine-associated hypermetabolic lymphadenopathy rates in myeloma and lymphoma patients. Note on the lower row the significant lower VAHL rates in lymphoma patients treated recently with anti-CD20 antibody containing therapy. All-PET group refers to all patients with hematologic malignancy that underwent $\left[{ }^{18} \mathrm{~F}\right] \mathrm{FDG}$ PET-CT after BNT162b2 administration. PET-1 group includes those received the first vaccine dose only before imaging, and PET-2 group includes those received the booster dose as well. ${ }^{\text {a }}$ : a statistically significant difference of no VAHL rates was found between compared groups, ${ }^{\text {b }}$ : a statistically significant difference of grade 1-2 VAHL rates was found between compared groups; ${ }^{\text {c: }}$ a statistically significant difference of grade 3-4 VAHL rates was found between compared groups; tx, therapy
21-34.5) days. Thirty-eight of them had their imaging study after the booster vaccine dose, and the median interval between imaging and serology analysis was 0.5 (IQR $-12-8)$ days.

In 20 patients the serology result was negative (all had antispike antibodies concentration $\leq 0.40 \mathrm{U} / \mathrm{mL}$ ), 16 patients had a low anti-spike titers (median antibody concentration 7.6, IQR 4.8-110.9 U/mL), and 18 patients had high anti-spike titers (median antibody concentration 688.4, IQR 426.2$1416 \mathrm{U} / \mathrm{mL}$ ). As presented on Table 4, the three groups did not differ significantly in terms of age, gender, and disease composition. The incidence of VAHL differed significantly between the three groups: only 2 of $20(10 \%)$ patients with negative serology showed VAHL on imaging, while $31.3 \%$ of those with low anti-spike titers and $72.2 \%$ of those with high anti-spike titers had VAHL on their PET study. Figure 2 (upper row) illustrates that VAHL grades were different as well between the groups and that the differences were more prominent in the patients having their $\left[{ }^{18} \mathrm{~F}\right] \mathrm{FDG}$ PET-CT after the booster vaccine dose.

Calculation of the predictive values of $\left[{ }^{18} \mathrm{~F}\right] \mathrm{FDG}$ PET-CT in predicting the humoral immunity and potential to have a positive post-vaccination serology is illustrated in Fig. 2, 
Table 4 Patients characteristics in different serology-based groups

\begin{tabular}{|c|c|c|c|c|}
\hline & $\begin{array}{l}\text { negative serology } \\
(\mathrm{n}=20)\end{array}$ & $\begin{array}{l}\text { low titer } \\
(n=16)\end{array}$ & $\begin{array}{l}\text { high titer } \\
(n=18)\end{array}$ & $\mathrm{Pv}$ \\
\hline Age (years) & $73.21(66.13-77.98)$ & $65.28(54.71-75.45)$ & $66.00(48.74-76.51)$ & 0.220 \\
\hline Male & $13(65 \%)$ & $9(56.3 \%)$ & $10(55.6 \%)$ & 0.804 \\
\hline $\begin{array}{l}\text { Lymphoma } \\
\text { Myeloma }\end{array}$ & $\begin{array}{l}16(80 \%) \\
4(20 \%)\end{array}$ & $\begin{array}{l}7(43.8 \%) \\
8(50 \%)\end{array}$ & $\begin{array}{l}10(55.6 \%) \\
8(44.4 \%)\end{array}$ & 0.084 \\
\hline CLL & $0(0 \%)$ & $1(6.3 \%)$ & $0(0 \%)$ & \\
\hline VAHL on PET-CT & $2(10 \%)$ & $5(31.3 \%)$ & $13(72.2 \%)$ & $<0.001^{\mathrm{b}, \mathrm{c}}$ \\
\hline VAHL on PET-CT after Vac-1 & $1 / 4(25 \%)$ & $1 / 6(16.7 \%)$ & $3 / 6(50 \%)$ & 0.358 \\
\hline VAHL on PET-CT after Vac-2 & $1 / 16(6.3 \%)$ & $4 / 10(40 \%)$ & $10 / 12(83.3 \%)$ & $<0.001^{\mathrm{a}, \mathrm{b}, \mathrm{c}}$ \\
\hline
\end{tabular}

Categorical variables are reported as frequency and percentage; Continuous variables are reported as median and IQR. Vac-1, first vaccine dose; Vac-2, booster vaccine dose

${ }^{\mathrm{a}}$ : a statistically significant difference found between negative serology and low titer groups

${ }^{\mathrm{b}}$ : a statistically significant difference found between negative serology and high titer groups

${ }^{\mathrm{c}}$ : a statistically significant difference found between low titer and high titer groups

lower row. The positive predictive values (PPV) were high: 90\% (95\% CI, 76.9-100\%) for All-PET patient and 93.3\% (95\% CI, 81.9-100\%) for PET-2 patients. Negative predicting values were low: $52.9 \%$ (95\% CI, 36.2-69.7\%) for All-PET patient and 65.2\% (95\% CI, 45.8-84.7\%) for PET-2 patients.

A Spearman's rank-order correlation was run to determine the relationship between serology-based and VAHL-based ranks. In the total 54 patients, there was a positive correlation between the variables, which was statistically significant $\left(\mathrm{r}_{\mathrm{s}}=\right.$ $0.530, \mathrm{Pv}<0.001)$. No statistically significant correlation was observed in the population of 16 PET- 1 patients $\left(r_{s}=0.279\right.$, $\mathrm{Pv}=0.295)$, but a stronger correlation was observed in the 38 PET-2 patients $\left(r_{s}=0.642, P v<0.001\right)$. Similar results were observed in subgroups of patients with lymphoma and myeloma separately (Fig. 3).

\section{Discussion}

The immune responses elicited by vaccines [31] are studied in depth lately, particularly since the introduction of the novel anti-SARS-CoV-2 mRNA vaccines [32-34]. After intramuscular administration of the vaccine, antigen-presenting cells (APCs) loaded with antigen migrate to regional lymph nodes, where they present peptide antigens and elicit two main responses: cellular response, with the formation of cytotoxic $\mathrm{T}$ lymphocytes capable of directly killing infected cells and humoral response, which depends on B cells proliferation in the germinal center $(\mathrm{GC})$ of the lymph node and the formation of matured B-cells as antibody secreting plasma cells and memory B-cells [32].

Recent studies have highlighted the prominent GC response elicited by mRNA vaccines in the lymph nodes reactive to the vaccine, and the pivotal role the $\mathrm{GC}$ response plays in the humoral response [33, 34]. Lederer et al. showed the stronger GC response elicited by SARS-CoV-2 mRNA vaccine compared with recombinant protein formulated vaccine [33]. A recent study by Ellebedy et al. that also included fine needle aspirates of draining axillary lymph nodes emphasizes how the robust and persistent $\mathrm{GC}$ B cell response is essential for durable humoral immunity [34].

In this study, we aimed to investigate the correlation between VAHL and the humoral response elicited by Covid-19 vaccine in patients with hematologic malignancy. $\left[{ }^{18} \mathrm{~F}\right] \mathrm{FDG}-$ positivity in ASLN ipsilateral to the vaccine injection site reflects hypermetabolism and proliferation of cells within the involved lymph nodes. A group of patients that were recently treated with anti-CD20 antibodies were our model for B cell depletion. The significant lower rates of VAHL observed in this patient group enforce the possibility that VAHL is a reflection of GC B cell proliferation as part of the early stage of the humoral response to vaccination. This observation motivated us to further explore the correlation between VAHL and the later stage of the humoral response: antibody secretion as assessed by serologic testing.

We identified in this study a subgroup of 54 patients with hematologic malignancy that had $\left[{ }^{18} \mathrm{~F}\right]$ FDG PET-CT study after vaccination and also had post-vaccination serologic testing. The finding of VAHL on imaging was found to be concordant with serology results: VAHL incidence was the highest among patients with high antispike titers, and the finding of VAHL showed an overall PPV of $90 \%$ in predicting post-vaccination serology positivity. Statistically significant positive correlation was found between VAHL-based and serology-based ranks. 
All-PET patients
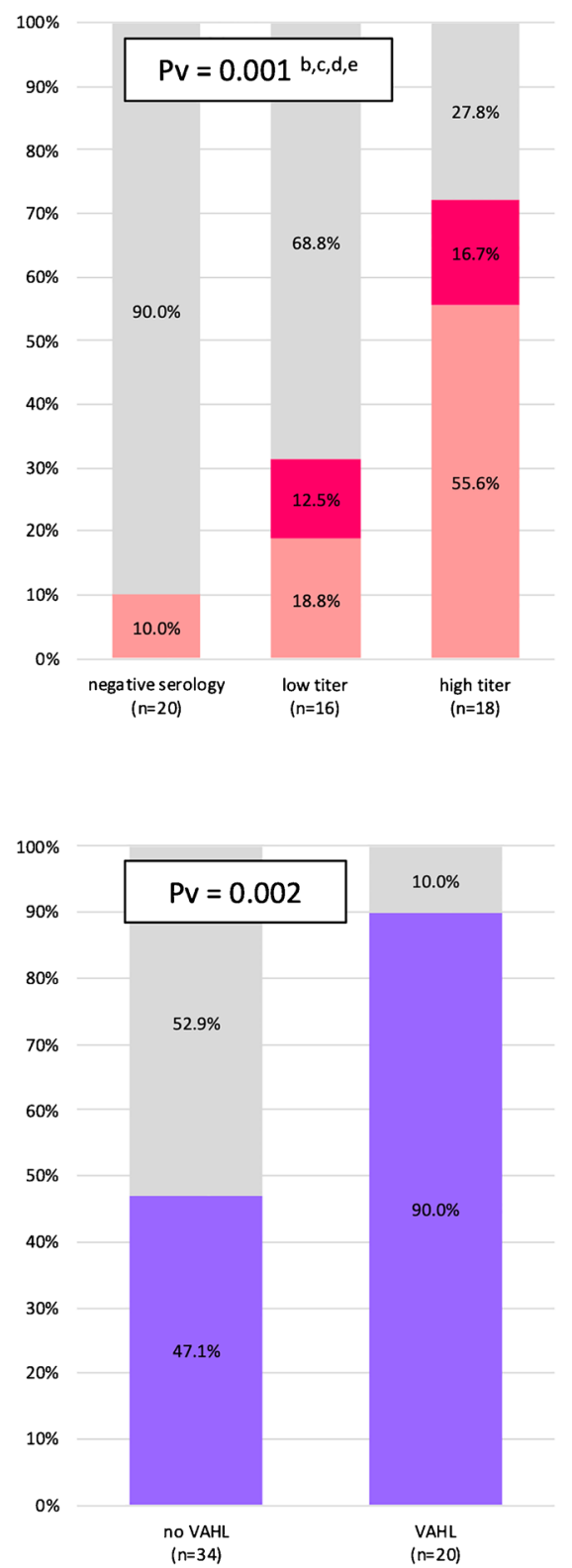

Fig. 2 Upper row: Vaccine-associated hypermetabolic lymphadenopathy rates in serology-based groups. Note the low rates of VAHL in patients with negative serology result. Lower row: Note the significant higher positive serology rate in patients with VAHL on imaging. All-PET group refers to all patients with hematologic malignancy that underwent $\left[{ }^{18}\right.$ F]FDG PET-CT after BNT162b2 administration. PET-2 group includes those received the first and booster vaccine doses before imaging. a: a statistically significant difference of no VAHL rates was found

All of the above results were more prominent in patients having a $\left[{ }^{18} \mathrm{~F}\right]$ FDG PET-CT study after the booster dose of the vaccine. This positive correlation indicates that the detection VAHL suggests an effective humoral response and a higher likelihood that antibodies may be produced.
PET-2 patients
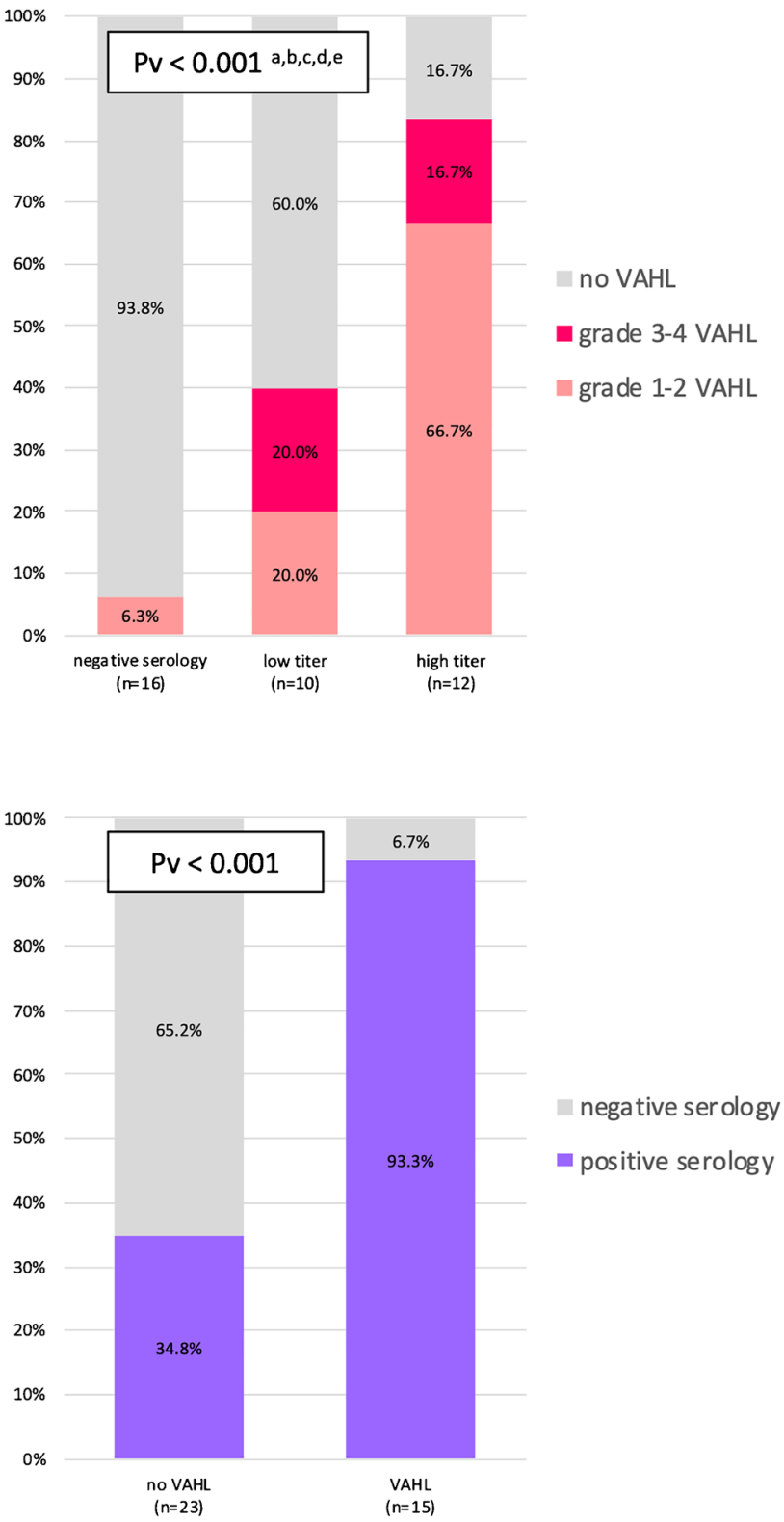

between negative serology and low titer groups; ${ }^{\text {b}}$ : a statistically significant difference of no VAHL rates was found between negative serology and high titer groups; ${ }^{c}$ : a statistically significant difference of no VAHL rates was found between low titer and high titer groups; ${ }^{\mathrm{d}}$ : a statistically significant difference of grade 1-2 VAHL rates was found between negative serology and high titer groups; ${ }^{\text {e}}$ : a statistically significant difference of grade 1-2 VAHL rates was found between low titer and high titer groups

However, one should not consider the absence of VAHL on PET as indicative of impaired humoral response and keep in mind that until future studies investigate other patient populations, the generalizability of our results is limited to patients with hematologic malignancy. 
All-PET patients

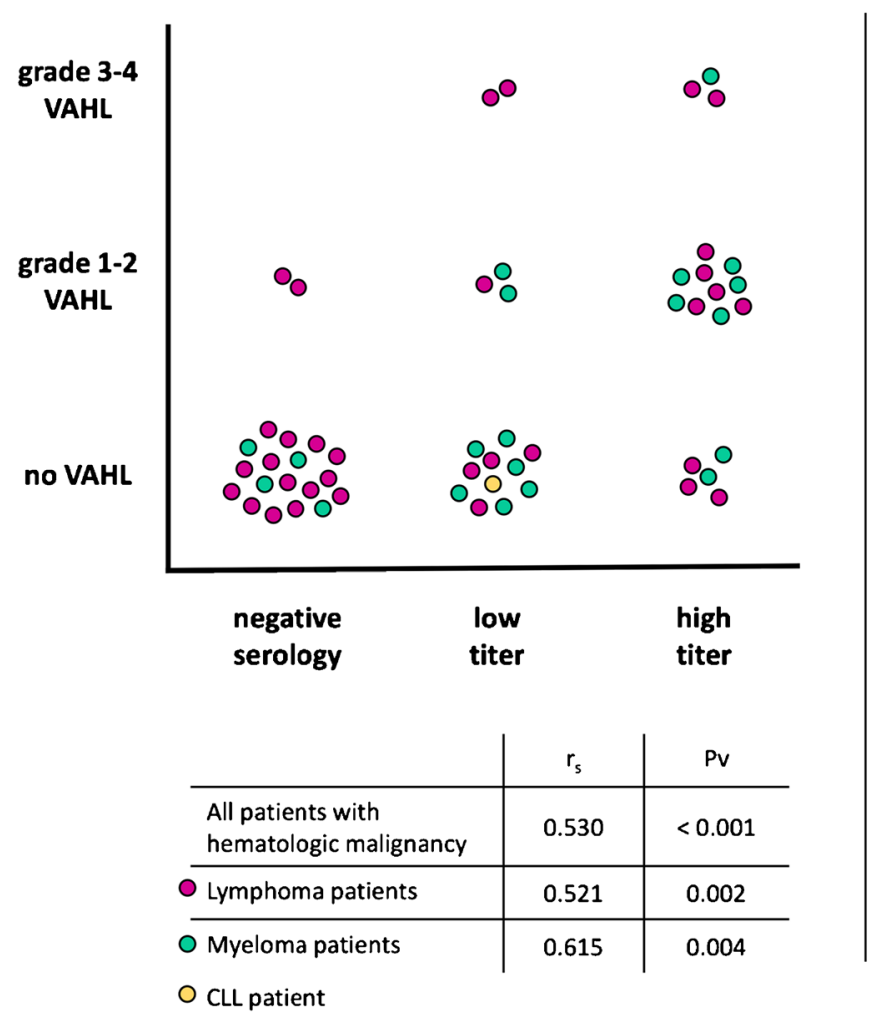

PET-2 patients

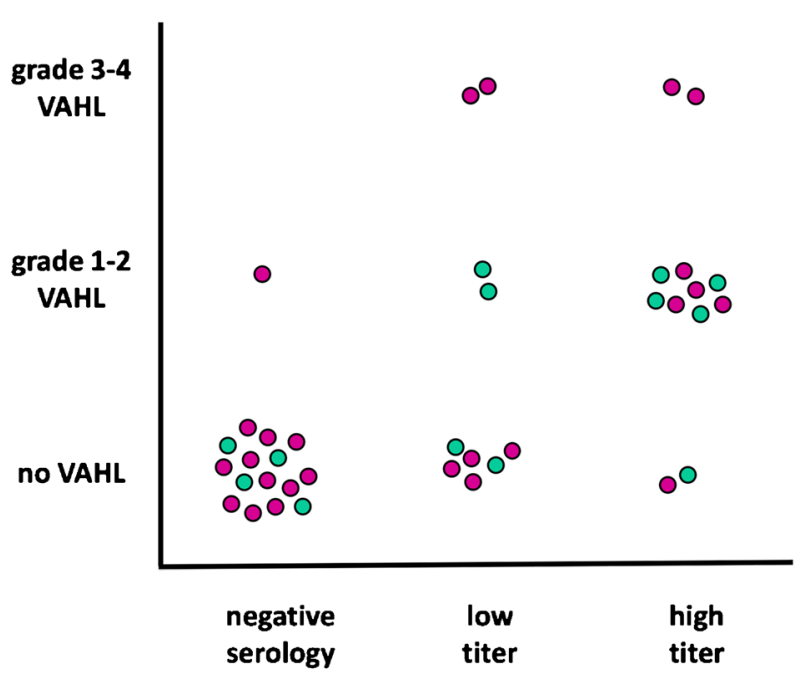

\begin{tabular}{l|c|c} 
& $r_{s}$ & $P v$ \\
\hline $\begin{array}{l}\text { All patients with } \\
\text { hematologic malignancy }\end{array}$ & 0.642 & $<0.001$ \\
\hline $\begin{array}{l}\text { Lymphoma patients } \\
\text { O Myeloma patients }\end{array}$ & 0.639 & 0.001 \\
\hline
\end{tabular}

Fig. 3 Correlation between serology-based and VAHL-based ranks. All-PET group refers to all patients with hematologic malignancy that underwent $\left[{ }^{18}\right.$ F $]$ FDG PET-CT after BNT162b2 administration. PET-2 group includes those received the first and booster vaccine doses before imaging

\section{Conclusions}

In patients with hematologic malignancy, VAHL detected on $\left[{ }^{18}\right.$ F]FDG PET-CT positively correlates with antibodymediated immune response to Covid-19 vaccine and is barely observed in patients exposed to anti-CD20 antibody containing therapy during the last year prior vaccination.

\footnotetext{
Abbreviations HLN, Hypermetabolic lymphadenopathy; VAHL, Vaccine-associated hypermetabolic lymphadenopathy; MHL, Malignant hypermetabolic lymphadenopathy; ASLN, Axillary or supraclavicular lymph nodes; $\left[{ }^{18} \mathrm{~F}\right] \mathrm{FDG},{ }^{18} \mathrm{~F}$-fluorodeoxyglucose; PET-CT, Positron emission tomography - computed tomography; SUV, Standardized uptake value; MIP, Maximal intensity projection; mRNA, Messenger ribonucleic acid; SARS-CoV-2, Severe acute respiratory syndrome coronavirus 2; Covid-19, Coronavirus disease 2019; CLL, Chronic lymphocytic leukemia; CD20, Cluster of differentiation 20; APC, Antigen presenting cell; GC, Germinal center; Pv, $P$ Value; IQR, Interquartile range; CI, Confidence interval; $r_{s}$, Spearman's rank correlation coefficient
}

Availability of data and materials The datasets used and/or analyzed during the current study are available from the corresponding author on reasonable request.

\section{Declarations}

Ethics approval and consent to participate All procedures performed in studies involving human participants were in accordance with the ethical standards of the institutional and/or national research committee and with the 1964 Helsinki Declaration and its later amendments or comparable ethical standards. All included imaging data was collected as part of a retrospective study protocol approved by the local institutional ethics committee which waived written informed consent (Reference ID 0056-21-TLV). All included patient that had post-vaccination serology testing provided informed consent and took part in a prospective study approved by the institutional review board (Reference ID 1068-20-TLV) and registered in ClinicalTrials.gov (number NCT04746092, registered February 9, 2021).

Consent for publication Not applicable.

Competing interests $\mathrm{YH}$ reports honoraria from AbbVie, Janssen, AstraZeneca, and Roche outside the submitted work. All other authors have no relevant financial or non-financial interests to disclose and have no conflicts of interest to declare that are relevant to the content of this article.

\section{References}

1. Polack FP, Thomas SJ, Kitchin N, Absalon J, Gurtman A, Lockhart S, et al. Safety and efficacy of the BNT162b2 mRNA Covid-19 vaccine. N Engl J Med. 2020;383(27):2603-15. https://doi.org/10. 1056/NEJMoa2034577. 
2. Boyarsky BJ, Werbel WA, Avery RK, Tobian AA, Massie AB, Segev DL, et al. Immunogenicity of a single dose of SARS-CoV2 messenger RNA vaccine in solid organ transplant recipients. JAMA. 2021. https://doi.org/10.1001/jama.2021.4385.

3. Monin-Aldama L, Laing AG, Munoz-Ruiz M, McKenzie DR, del Barrio ID, Alaguthurai T, et al. Interim results of the safety and immune-efficacy of 1 versus 2 doses of COVID-19 vaccine BNT162b2 for cancer patients in the context of the UK vaccine priority guidelines. medRxiv. 2021. https://doi.org/10.1101/2021. 03.17.21253131

4. Sahin U, Muik A, Derhovanessian E, Vogler I, Kranz LM, Vormehr M, et al. COVID-19 vaccine BNT162b1 elicits human antibody and TH $1 \mathrm{~T}$ cell responses. Nature. 2020;586(7830):594 9. https://doi.org/10.1038/s41586-020-2814-7.

5. Thakkar A, Pradhan K, Jindal S, Cui Z, Rockwell B, Shah AP, et al. Patterns of seroconversion for SARS-CoV-2 IgG in patients with malignant disease and association with anticancer therapy. Nat Cancer. 2021;22:1-8. https://doi.org/10. 1038/s43018-021-00191-y.

6. Subesinghe S, Bechman K, Rutherford AI, Goldblatt D, Galloway JB. A systematic review and metaanalysis of antirheumatic drugs and vaccine immunogenicity in rheumatoid arthritis. J Rheumatol. 2018;45(6):733-44. https://doi.org/10. 3899/jrheum. 170710.

7. Bingham CO III, Looney RJ, Deodhar A, Halsey N, Greenwald M, Codding $\mathrm{C}$, et al. Immunization responses in rheumatoid arthritis patients treated with rituximab: results from a controlled clinical trial. Arthritis Rheum. 2010;62(1):64-74. https://doi.org/10.1002/ art.25034.

8. Eisenberg RA, Jawad AF, Boyer J, Maurer K, McDonald K, Prak ET, et al. Rituximab-treated patients have a poor response to influenza vaccination. J Clin Immunol. 2013;33(2):388-96. https://doi. org/10.1007/s10875-012-9813-x.

9. Sonani B, Aslam F, Goyal A, Patel J, Bansal P. COVID-19 vaccination in immunocompromised patients. Clin Rheumatol. 2020;25: 1-2. https://doi.org/10.1007/s10067-020-05547-w.

10. Furer V, Rondaan C, Agmon-Levin N, Van Assen S, Bijl M, Kapetanovic MC, et al. Point of view on the vaccination against COVID-19 in patients with autoimmune inflammatory rheumatic diseases. RMD open. 2021;7(1):e001594. https://doi.org/10.1136/ rmdopen-2021-001594.

11. American College of Rheumatology. COVID-19 Vaccine Clinical Guidance Summary for Patients with Rheumatic and Musculoskeletal Diseases. https://www.rheumatology.org/Portals/ 0/Files/COVID-19-Vaccine-Clinical-Guidance-RheumaticDiseases-Summary.pdf. Accessed 4 April 2021.

12. Pierpont TM, Limper CB, Richards KL. Past, present, and future of rituximab - the world's first oncology monoclonal antibody therapy. Front Oncol. 2018;8:163. https://doi.org/10.3389/fonc.2018. 00163.

13. Becker AS, Perez-Johnston R, Chikarmane SA, Chen MM, El Homsi M, Feigin KN, et al. Multidisciplinary recommendations regarding post-vaccine Adenopathy and radiologic imaging: radiology scientific expert panel. Radiology. 2021;24:210436. https:// doi.org/10.1148/radiol.2021210436.

14. Mortazavi S. Coronavirus disease (COVID-19) vaccination associated axillary Adenopathy: imaging findings and follow-up recommendations in 23 women. Am J Roentgenol. 2021. https://doi.org/ 10.2214/AJR.21.25651

15. Edmonds CE, Zuckerman SP, Conant EF. Management of unilateral axillary lymphadenopathy detected on breast MRI in the era of coronavirus disease (COVID-19) vaccination. Am J Roentgenol. 2021. https://doi.org/10.2214/AJR.21.25604.

16. Lehman CD, Lamb LR, D'Alessandro HA. Mitigating the impact of coronavirus disease (COVID-19) vaccinations on patients undergoing breast imaging examinations: a pragmatic approach. Am J Roentgenol. 2021. https://doi.org/10.2214/AJR.21.25688.

17. Özütemiz C, Krystosek LA, Church AL, Chauhan A, Ellermann JM, Domingo-Musibay E, et al. Lymphadenopathy in COVID-19 vaccine recipients: diagnostic dilemma in oncology patients. Radiology. 2021;24:210275. https://doi.org/10.1148/radiol. 2021210275.

18. Mehta N, Sales RM, Babagbemi K, Levy AD, McGrath AL, Drotman M, et al. Unilateral axillary Adenopathy in the setting of COVID-19 vaccine. Clin Imaging. 2021;75:12-5. https://doi.org/ 10.1016/j.clinimag.2021.01.016.

19. Ahn RW, Mootz AR, Brewington CC, Abbara S. Axillary lymphadenopathy after mRNA COVID-19 vaccination. Radiol: Cardiothorac Imaging. 2021;3(1):e210008. https://doi.org/10. 1148/ryct.2021210008.

20. Eifer M, Eshet Y. Imaging of COVID-19 vaccination at FDG PET/ CT. Radiology. 2021. https://doi.org/10.1148/radiol.2020210030.

21. Hanneman K, Iwanochko RM, Thavendiranathan P. Evolution of lymphadenopathy at PET/MRI after COVID-19 vaccination. Radiology. 2021;24:210386. https://doi.org/10.1148/radiol. 2021210386.

22. Nawwar AA, Searle J, Singh R, Lyburn ID. Oxford-AstraZeneca COVID-19 vaccination induced lymphadenopathy on $[18 \mathrm{~F}]$ choline PET/CT - not only an FDG finding. Eur J Nucl Med Mol Imaging. 2021;4:1-2. https://doi.org/10.1007/s00259-021-052792.

23. Nawwar AA, Searle J, Hagan I, Lyburn ID. COVID-19 vaccination induced axillary nodal uptake on [18F] FDG PET/CT. Eur J Nucl Med Mol Imaging. 2021;26:1-2. https://doi.org/10.1007/s00259021-05274-7.

24. Avner M, Orevi M, Caplan N, Popovtzer A, Lotem M, Cohen JE. COVID-19 vaccine as a cause for unilateral lymphadenopathy detected by $18 \mathrm{~F}-\mathrm{FDG}$ PET/CT in a patient affected by melanoma. Eur J Nucl Med Mol Imaging. 2021;6:1-2. https://doi.org/10.1007/ s00259-021-05278-3.

25. Moghimi S, Wilson D, Martineau P. FDG PET Findings postCOVID vaccinations: signs of the times? Clin Nucl Med. 2021. https://doi.org/10.1097/RLU.0000000000003636.

26. Cohen D, Krauthammer SH, Wolf I, Even-Sapir E. Hypermetabolic lymphadenopathy following administration of BNT162b2 mRNA Covid-19 vaccine: incidence assessed by $[18$ F] FDG PET-CT and relevance to study interpretation. Eur J Nucl Med Mol Imaging. 2021;27:1-0. https://doi. org/10.1007/s00259-021-05314-2.

27. Panagiotidis E, Exarhos D, Housianakou I, Bournazos A, Datseris I. FDG uptake in axillary lymph nodes after vaccination against pandemic (H1N1). Eur Radiol. 2010;20(5):1251-3. https://doi. org/10.1007/s00330-010-1719-5.

28. Burger IA, Husmann L, Hany TF, Schmid DT, Schaefer NG. Incidence and intensity of F-18 FDG uptake after vaccination with H1N1 vaccine. Clin Nucl Med. 2011;36(10):848-53. https://doi. org/10.1097/RLU.0b013e3182177322.

29. Coates EE, Costner PJ, Nason MC, Herrin DM, Conant S, Herscovitch P, et al. Lymph node activation by PET/CT following vaccination with licensed vaccines for human papillomaviruses. Clin Nucl Med. 2017;42(5):329-34. https://doi.org/10.1097/RLU. 0000000000001603.

30. Dagan N, Barda N, Kepten E, Miron O, Perchik S, Katz MA, et al. BNT162b2 mRNA Covid-19 vaccine in a nationwide mass vaccination setting. N Engl J Med. 2021. https://doi.org/10.1056/ NEJMoa2101765.

31. Pal I, Ramsey JD. The role of the lymphatic system in vaccine trafficking and immune response. Adv Drug Deliv Rev. 2011;63(10-11):909-22. https://doi.org/10.1016/j.addr.2011.05. 018 . 
32. Bettini E, Locci M. SARS-CoV-2 mRNA vaccines: immunological mechanism and beyond. Vaccines. 2021;9(2):147. https://doi.org/ $10.3390 /$ vaccines 9020147 .

33. Lederer K, Castaño D, Atria DG, Oguin TH III, Wang S, Manzoni TB, et al. SARS-CoV-2 mRNA vaccines foster potent antigenspecific germinal center responses associated with neutralizing antibody generation. Immunity. 2020;53(6):1281-95. https://doi.org/ 10.1016/j.immuni.2020.11.009.
34. Ellebedy A, Turner J, O'Halloran J, et al. SARS-CoV-2 mRNA vaccines induce a robust germinal centre reaction in humans. Res Square. 2021. https://doi.org/10.21203/rs.3.rs-310773/v1.

Publisher's note Springer Nature remains neutral with regard to jurisdictional claims in published maps and institutional affiliations. 